ORIGINAL RESEARCH

\title{
Performance Characteristics of the Second-Generation Remote Emergency Medical Oxygen Closed-Circuit Rebreather
}

\author{
Neal W. Pollock, PhD; Michael J. Natoli, MS \\ From the Center for Hyperbaric Medicine and Environmental Physiology, Duke University Medical Center, Durham, NC (Dr Pollock and \\ Mr Natoli); and the Divers Alert Network, Durham, NC (Dr Pollock).
}

\begin{abstract}
Objective.-Closed-circuit oxygen rebreathers may provide high concentrations of oxygen at extremely low flow rates appropriate for field use with limited oxygen supplies. The performance of the preproduction, second-generation remote emergency medical oxygen $\left(\mathrm{REMO}_{2}\right)$ system developed for Divers Alert Network was evaluated.

Methods. - The unidirectional circuit was made up of a solid, prepackaged $\mathrm{CO}_{2}$ scrubber canister (984 \pm 14 [SD] g scrubber mass), standard 22-mm-inside-diameter anesthesia circuit hoses, 5-L breathing bag, 5-cm $\mathrm{H}_{2} \mathrm{O}$ positive end-expiratory pressure valve, and oronasal mask. Oxygen flow, inspired oxygen, expired $\mathrm{CO}_{2}$, peak inspired and expired mask pressures, time to reach scrubber canister saturation or "breakthrough" (postscrubber $\mathrm{CO}_{2}$ concentration reaching $3.8 \mathrm{~mm} \mathrm{Hg}$ ), and subject tolerance were measured under standard laboratory conditions.

Results.-Six trials were completed using healthy volunteers $(94.7 \pm 19.6 \mathrm{~kg})$. Five of the 6 completed trials did not reach breakthrough at the planned trial limit of 8 hours. Mean average oxygen flow rate was $1.00 \pm 0.17 \mathrm{~L} \cdot \mathrm{min}^{-1}$. Mean peak inspired and expired mask pressures were $-5.0 \pm$ 1.9 and $6.5 \pm 1.9 \mathrm{~cm} \mathrm{H}_{2} \mathrm{O}$, respectively. Subjects generally reported good tolerance to circuit breathing.

Conclusions.- The second-generation $\mathrm{REMO}_{2}$ was well tolerated by healthy subjects during 8-hour laboratory evaluation trials. The device provided high mean inspired oxygen fractions at low mean oxygen flow rates, relatively modest mean maximal inspired and expired pressures, and excellent scrubber canister duration. Further evaluation of field performance with a patient population is warranted.
\end{abstract}

Key words: carbon dioxide scrubber, diving, first aid, oxygen

\section{Introduction}

Oxygen is provided as a primary or adjunctive therapy in a number of acute and chronic medical conditions. Effective treatment often requires delivery of the highest oxygen concentration possible until arrival at a medical center. The ability to deliver high concentrations of oxygen in the prehospital environment is generally limited by the gas supply and the type of delivery system available to the prehospital provider. Weight and space lim-

Presented in part at the Wilderness Medical Society Conference, Snowmass, CO, July 26, 2005.

Corresponding author: Neal W. Pollock, PhD, Center for Hyperbaric Medicine and Environmental Physiology, Box 3823, Duke University Medical Center, Durham, NC 27710 (e-mail: neal.pollock@duke.edu). itations typically determine available equipment, particularly in remote locations. Open-circuit systems, which allow exhaled gas to escape to the atmosphere, are simple and easy to use but tend to be inefficient in the use of the oxygen supply and often poor in the fraction of oxygen delivered. Closed-circuit systems, which allow rebreathing of unused oxygen after carbon dioxide is removed from the exhaled gas, are more complicated but tend to deliver higher concentrations of oxygen at substantially lower oxygen flow rates.

Divers Alert Network (DAN) began a program to develop a portable, closed-circuit oxygen rebreather for field surface emergency use in 1997 after several promising reports appeared in the literature. ${ }^{1-3}$ The first-generation remote emergency medical oxygen $\left(\mathrm{REMO}_{2}\right)$ de- 
Table 1. Participant characteristics

\begin{tabular}{|c|c|c|c|c|c|c|c|c|}
\hline Subject & Gender & Age (years) & Weight (kg) & Height (m) & $\begin{array}{c}\text { Body Fat* } \\
\text { (\%) }\end{array}$ & $\begin{array}{c}\text { Resting } V_{E}^{\dagger} \\
\left(L \cdot \mathrm{min}^{-1}\right)\end{array}$ & $\begin{array}{l}\text { Resting } \mathrm{VO}_{2} \dagger \\
\quad\left(\mathrm{L} \cdot \mathrm{min}^{-1}\right)\end{array}$ & $\begin{array}{l}\text { Resting } \mathrm{VCO}_{2} \dagger \\
\quad\left(\mathrm{L} \cdot \mathrm{min}^{-1}\right)\end{array}$ \\
\hline 1 & M & 35 & 125.9 & 1.91 & 27.5 & 14.4 & 0.44 & 0.43 \\
\hline 2 & $\mathrm{~F}$ & 20 & 72.7 & 1.7 & 28.2 & 11.2 & 0.31 & 0.32 \\
\hline 3 & M & 43 & 76.4 & 1.73 & 19 & 11.8 & 0.36 & 0.38 \\
\hline 4 & M & 30 & 103.6 & 1.85 & 20.4 & 10.4 & 0.38 & 0.32 \\
\hline 5 & M & 38 & 89.5 & 1.88 & 22.1 & 11.3 & 0.35 & 0.32 \\
\hline 6 & M & 46 & 100 & 1.78 & 16 & 10.4 & 0.34 & 0.32 \\
\hline Mean & & 35.3 & 94.7 & 1.81 & 22.2 & 11.6 & 0.36 & 0.35 \\
\hline SD & & 9.4 & 19.6 & 0.08 & 4.8 & 1.5 & 0.04 & 0.05 \\
\hline
\end{tabular}

*Body composition (percent body fat) estimated by 7-site skinfold measurement using Harpenden calipers. ${ }^{4}$

$\dagger$ Resting minute ventilation $\left(\mathrm{V}_{\mathrm{E}}\right)$, oxygen consumption $\left(\mathrm{VO}_{2}\right)$, and $\mathrm{CO}_{2}$ volume measured at the mouth $\left(\mathrm{VCO}_{2}\right)$.

vice was produced as a result in 1999. The system was discontinued when the supply of the $\mathrm{CO}_{2}$ scrubber canisters was curtailed. The second-generation $\mathrm{REMO}_{2}$ was developed as an entirely new circuit. Our purpose was to evaluate the performance of the latest unit.

\section{Methods}

The Institutional Review Board of Duke University Medical Center approved the test protocol. Six healthy and moderately fit volunteers (5 men and 1 woman) completed one trial each. Height and weight were measured with standard clinical laboratory devices. Percent body fat was estimated from 7-site skinfold thickness measures (Harpenden Caliper; British Indicators, Burgess Hill, West Sussex, UK) with sex/race-specific equations. ${ }^{4}$ Resting measures of minute ventilation $\left(\mathrm{V}_{\mathrm{E}}\right)$, oxygen consumption $\left(\mathrm{VO}_{2}\right)$, and expired $\mathrm{CO}_{2}$ volume $\left(\mathrm{VCO}_{2}\right)$ were recorded just before the start of each trial. Descriptive characteristics are shown in Table 1.

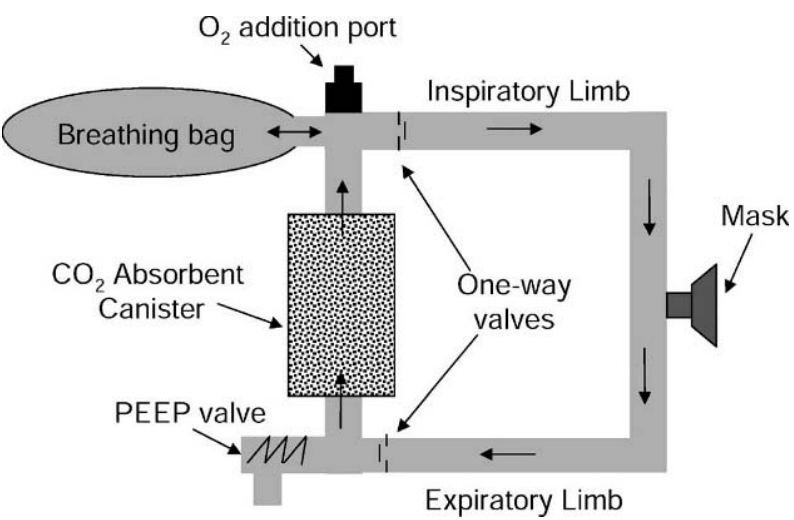

Figure 1. Schematic of $\mathrm{REMO}_{2}$ oxygen rebreather system.
Summary data are presented as mean \pm SD, with ranges where appropriate.

The second-generation $\mathrm{REMO}_{2}$ system was a circuit providing unidirectional flow through a $\mathrm{CO}_{2}$ absorbent bed. The device was made up of 2 major components: 1) a respiratory circuit (Engineered Medical Systems [EMS] Inc, Indianapolis, IN) and 2) a solid, prepackaged $\mathrm{CO}_{2}$ absorbent (Micropore ExtendAir, Newark, DE). The respiratory circuit consisted of an oronasal SealFlex (EMS Inc, Indianapolis, IN) mask (size large), connected to expandable tubing (22 $\mathrm{mm}$ inside diameter [ID], 55 $\mathrm{cm}$ long collapsed, $183 \mathrm{~cm}$ long fully extended) through a 22-mm-ID elbow fitting attached to a parallel limb "wye" fitting. The expiratory limb of the circuit included the tubing connecting 1 side of the "wye" fitting to a "Tee" fitting (22 mm ID) at the inlet of the $\mathrm{CO}_{2}$ canister. The "Tee" fitting was connected to the canister inlet port (22 $\mathrm{mm}$ outside diameter [OD]) through a 22mm-ID elbow fitting on 1 side, a $5-\mathrm{cm}_{2} \mathrm{O}$ positive end-expiratory pressure (PEEP) valve on another side, and a one-way valve (18-mm-diameter leaflet) that connected the bottom of the "Tee" to the tubing. (Note: the one-way valve near the distal end of the expiratory limb was added during the evaluation trials to decrease $\mathrm{F}_{\mathrm{I}} \mathrm{CO}_{2}$. The change was incorporated into the production version of the second-generation system depicted in Figure 1.) The $\mathrm{CO}_{2}$ absorbent canister was a plastic tube with 2 prototype conical Plexiglas end caps (volume of $90 \mathrm{~mL}$ each) that held the solid $\mathrm{CO}_{2}$ absorbent insert. The canister outlet port (22 mm OD) was connected to the bottom of a "Tee" with an oxygen addition fitting opposite the canister connection, 1 side of the "Tee" connected to a 5-L breathing bag, and the other side of the "Tee" connected to a one-way valve that was attached to tubing connected to the "wye" fitting at the 
mask. The total noncompliant volume of the system was estimated to be $1723 \mathrm{~mL}$ (1120 mL within tubing, 180 $\mathrm{mL}$ within canister end caps, $173 \mathrm{~mL}$ within connectors, and $250 \mathrm{~mL}$ within the mask). The dead space was 275 $\mathrm{mL}$.

Respiratory gases and pressures within the circuit are not measured under normal operating conditions. Three 22-mm-ID "Tee" adapters, two 22-mm-ID/OD couplers, and eight 22-mm-ID silicone rubber adapters were added to the system to accommodate the following test devices: mask gas, pressure, and temperature sample ports; gas sample return ports; a canister exit $\mathrm{CO}_{2}$ sample and thermister port; and a volume measurement device. These adapters added $75 \mathrm{~mL}$ of dead space in the test mode.

Oxygen was provided from an E-cylinder fitted with a model 32-29-5209 oxygen regulator with preset (nominal) flows from 0.25 to $25 \mathrm{~L} \cdot \mathrm{min}^{-1}$ (Allied Healthcare Products Inc, St Louis, MO). The calibrated flow rate was determined for each nominal setting $(0.25=0.08$; $0.5=0.35 ; 1=0.96 ; 2=1.85 ; 4.0=3.69 ; 8=7.89$; $\left.15=14.78 \mathrm{~L} \cdot \mathrm{min}^{-1}\right)$.

Trials were conducted under stable, standard laboratory conditions (121 m [398 feet] altitude). Environmental measures were recorded every 10 minutes. Stable conditions of barometric pressure $(753.3 \pm 3.3 \mathrm{~mm} \mathrm{Hg})$, temperature $\left(22.2 \pm 0.6^{\circ} \mathrm{C}\right)$, and relative humidity $(43.2$ $\pm 1.0 \%)$ were maintained.

Trial measures included the following noninvasive values: $\mathrm{V}_{\mathrm{E}}$, oxygen flow rate, canister outlet temperature $\left(\mathrm{T}_{\text {can }}\right)$ and $\mathrm{CO}_{2}$ content at the canister outlet $\left(\mathrm{CO}_{2 \text { can }}\right)$, $\mathrm{CO}_{2}$ scrubber duration (breakthrough), inspired oxygen fraction $\left(\mathrm{F}_{\mathrm{I}} \mathrm{O}_{2}\right)$, inspired $\mathrm{CO}_{2}$ fraction $\left(\mathrm{F}_{\mathrm{I}} \mathrm{CO}_{2}\right)$, end-tidal oxygen fraction $\left(\mathrm{F}_{\mathrm{ET}} \mathrm{O}_{2}\right)$, end-tidal $\mathrm{CO}_{2}$ fraction $\left(\mathrm{F}_{\mathrm{ET}}\right.$ $\left.\mathrm{CO}_{2}\right)$, inspired $\left(\mathrm{Pm}_{\mathrm{in}}\right)$ and expired $\left(\mathrm{Pm}_{\mathrm{ex}}\right)$ oronasal mask pressures, and temperature in the mask $\left(\mathrm{T}_{\mathrm{m}}\right)$ and ambient air $\left(\mathrm{T}_{\mathrm{a}}\right)$. All data were collected on a Dell Optiplex computer, a component of the Consentius Technologies (Sandy, UT), Parvomedics TrueMax 2400 metabolic cart. $\mathrm{V}_{\mathrm{E}}$, oxygen flow rate, (gas) cylinder pressure (Pcyl), mask pressure (Pm), inspired and expired $\mathrm{O}_{2}$ and $\mathrm{CO}_{2}$, and $\mathrm{CO}_{2}$ can were measured at a rate of 50 samples $\cdot \mathrm{s}^{-1}$. Temperatures were measured at a rate of 40 samples $\cdot \mathrm{s}^{-1}$ on a Power Macintosh 7600/120 using MacLab/16s hardware and PowerLab version 4.0 software (ADInstruments, Castle Hill, New South Wales, Australia).

$\mathrm{O}_{2}$ flow rate was measured with a Fleisch pneumotachograph (\#001216; A. Fleisch, Phipps and Bird, Richmond, VA, $1 \mathrm{~cm} \mathrm{H}_{2} \mathrm{O}=8.928 \mathrm{~L} \cdot \mathrm{min}^{-1}$ ) and pancake transducer (model DP103-10; Validyne, Northridge, CA). The transducer was connected to a carrier demodulator (model CD19A; Validyne), which outputs a voltage proportional to flow. The pneumotachograph was calibrated using a model 922 rolling-seal spirometer (Sensormedics, Anaheim, CA) and a calibrated 3.0-L syringe (Series 5530; Hans Rudolf, Kansas City, MO). $\mathrm{O}_{2}$ flow was verified by calculating volume change over time using the Ideal Gas Law and the change in $\mathrm{O}_{2}$ supply pressure, corrected to standard temperature, pressure, dry (STPD) values.

Canister outlet $\mathrm{CO}_{2}$ samples were drawn continuously from the exit of the scrubber through a 1.6-mm-ID, 45$\mathrm{cm}$-long vinyl sample line at a flow rate of $0.25 \mathrm{~L} \cdot \mathrm{min}^{-1}$. Samples were delivered to a BCI (BCI International, Waukesha, WI) Capnocheck Plus $\mathrm{CO}_{2}$ analyzer modified for rapid analysis. $\mathrm{O}_{2}$ and $\mathrm{CO}_{2}$ levels were drawn from a point $4 \mathrm{~cm}$ from the mouth within the oronasal mask and delivered through a $1.6-\mathrm{mm}-\mathrm{ID}, 220-\mathrm{cm}$-long vinyl sample line to the gas analysis module of the Consentius Technologies (Sandy, UT), Parvomedics Truemax 2400 metabolic cart at a flow of $0.20 \mathrm{~L} \cdot \mathrm{min}^{-1}$. Mean $\mathrm{F}_{\mathrm{ET}} \mathrm{O}_{2}$ and $\mathrm{F}_{\mathrm{ET}} \mathrm{CO}_{2}$ were computed every 30 seconds. $\mathrm{F}_{\mathrm{I}} \mathrm{O}_{2}$ was computed as the mean of the maximum $\mathrm{O}_{2}$ concentration during each 30-second interval. Gas samples were returned to the circuit. The gas analysis module was calibrated using standard gas fractions of $1.00 \mathrm{O}_{2}$ and 0.16 $\mathrm{O}_{2} / 0.04 \mathrm{CO}_{2}$ (Scott Medical Products 03024784SR, Plumsteadville, PA). Expired $\mathrm{V}_{\mathrm{E}}$ was measured with a bag-in-box setup connected to the pneumotach module of the metabolic cart. The breathing bag of the test circuit was placed in a Plexiglas cylinder $(14 \mathrm{~cm}$ diameter, $30 \mathrm{~cm}$ length, $4.616 \mathrm{~L}$ volume) outfitted with a Hans Rudolf two-way nonreturn valve (model 2700) with the exhale side of the valve connected to the pneumotach.

Oronasal mask pressure was measured using a Validyne model MP 45-30 pressure transducer. The pressure transducer was calibrated using a Setra Systems (Boxborough, MA) electronic manometer, model 339-1. Oronasal mask pressures provide an indirect measure of breathing resistance. The mean of the extreme $\mathrm{Pm}_{\text {in }}$ and $\mathrm{Pm}_{\text {exp }}$ values provide an index of the breathing resistance created by the circuit.

$\mathrm{T}_{\mathrm{m}}$ was measured with a thermistor (model 729; Yellow Springs Instrument (Yellow Springs, OH) [0.3-second time constant]) and displayed by a temperature indicator (model 93100-00; Cole Parmer Instrument Co, Vernon Hills, IL) with an analog output to the Macintosh computer. Mask temperature was measured at the site of the $\mathrm{O}_{2}$ and $\mathrm{CO}_{2}$ sample port. $\mathrm{T}_{\text {can }}$ was measured with a Yellow Springs Instrument thermistor (model 729 [1.1second time constant]) and displayed by a temperature indicator (model H-08502-14; Cole Parmer Instrument Co) with an analog output to the Macintosh computer. $\mathrm{T}_{\text {can }}$ was measured in the air stream from the site of the inspired $\mathrm{CO}_{2}$ sample port at the exit of the canister.

Scrubber breakthrough was defined as the circuit 
breathing time until $\mathrm{CO}_{2}$ can reached $3.8 \mathrm{~mm} \mathrm{Hg}(0.005$ concentration at sea level pressure). This is commonly used to define scrubber saturation in rebreather circuit testing. ${ }^{5}$ The breakthrough time excluded air breaks.

Subjects underwent identical 8-hour tests in which they breathed on the $\mathrm{REMO}_{2}$ while physiologic parameters were measured. Maintenance oxygen flow was 0.5 $\mathrm{L} \cdot \mathrm{min}^{-1}$, with primary and secondary oxygen purges during each 2-hour breathing period.

Subjects remained at rest in a semirecumbent position for the duration of the trial, excluding a 10-minute air break provided every 2 hours, during which data collection was suspended. Primary $\mathrm{O}_{2}$ purging of the circuit was carried out after every air break. This was accomplished by setting the nominal $\mathrm{O}_{2}$ flow rate at $8 \mathrm{~L} \cdot \mathrm{min}^{-1}$, manually sealing the circuit with a hand until the breathing bag was full, and having the subject exhale fully before donning the mask to seal the circuit. Excess gas escaped through the PEEP valve during purging of inert gas. The $\mathrm{O}_{2}$ flow was reduced after the first 2 minutes to nominal $2 \mathrm{~L} \cdot \mathrm{min}^{-1}$. Flow was further reduced to a maintenance flow of nominal $0.5 \mathrm{~L} \cdot \mathrm{min}^{-1}$ after $10 \mathrm{~min}$ utes. The breathing bag was monitored closely, and flow was increased to restore volume if the bag approached collapse or reduced if the bag was too full. Secondary purging was completed after every 30 minutes of use. Flow was increased to nominal $8 \mathrm{~L} \cdot \mathrm{min}^{-1}$ for 1 minute, reduced to $2 \mathrm{~L} \cdot \mathrm{min}^{-1}$ for 5 minutes, and returned to the maintenance flow of $0.5 \mathrm{~L} \cdot \mathrm{min}^{-1}$.

Trials were terminated by subject choice, when $\mathrm{CO}_{2 \text { can }}$ reached breakthrough, or when the 8-hour total circuit breathing duration was reached.

\section{Results}

Six trials were completed to evaluate the second-generation rebreather circuit. The results are summarized in Table 2. One additional trial ended prematurely when the subject withdrew at 1 hour and 50 minutes. The subject expressed unacceptable personal discomfort (a throat irritation reminiscent of a sensation he had experienced before thyroid surgery). Because this occurred relatively early in the trial and the source of the effect could not be confirmed, all data from this run were excluded from consideration.

The $\mathrm{CO}_{2}$ absorbent removed virtually all of the $\mathrm{CO}_{2}$ from the circuit until saturation was approached. The climb preceding breakthrough was evident for only 1 subject. $\mathrm{CO}_{2}$ first began to accumulate for subject 4 after 373 minutes (6 hours and 13 minutes). Breakthrough was reached in 470 minutes ( 7 hours and 50 minutes). The time course for $\mathrm{CO}_{2}$ can and $\mathrm{F}_{\mathrm{I}} \mathrm{O}_{2}$ for subject 4 are shown in Figure 2. Of the 5 trials not reaching break-

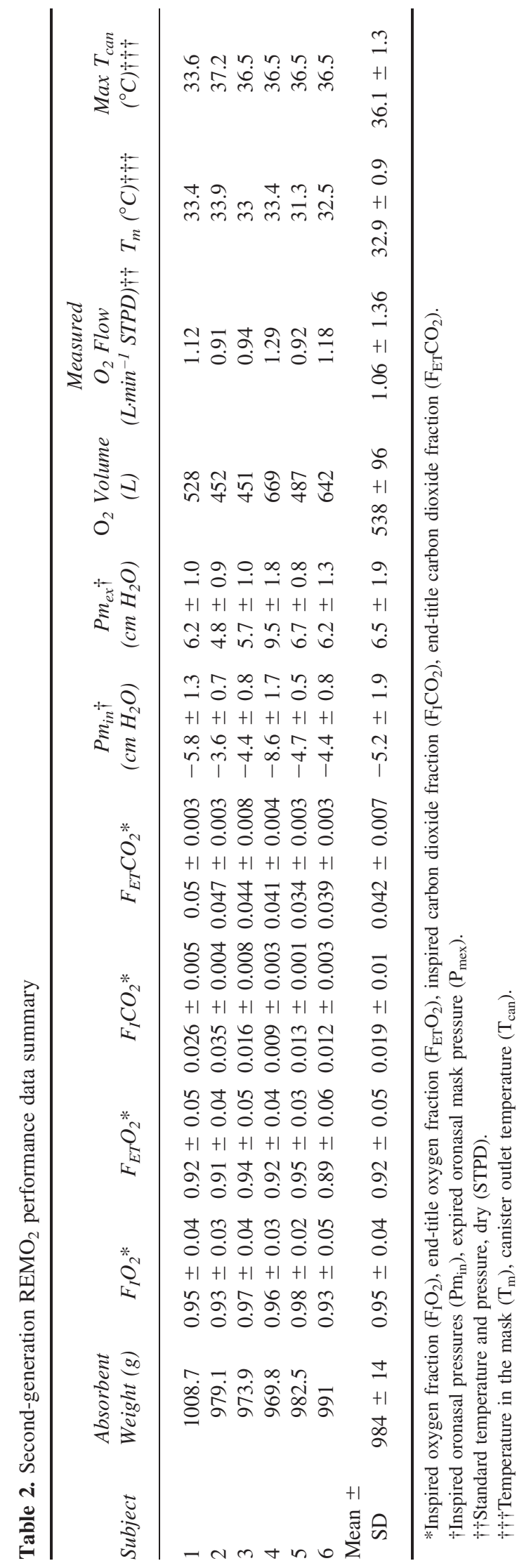



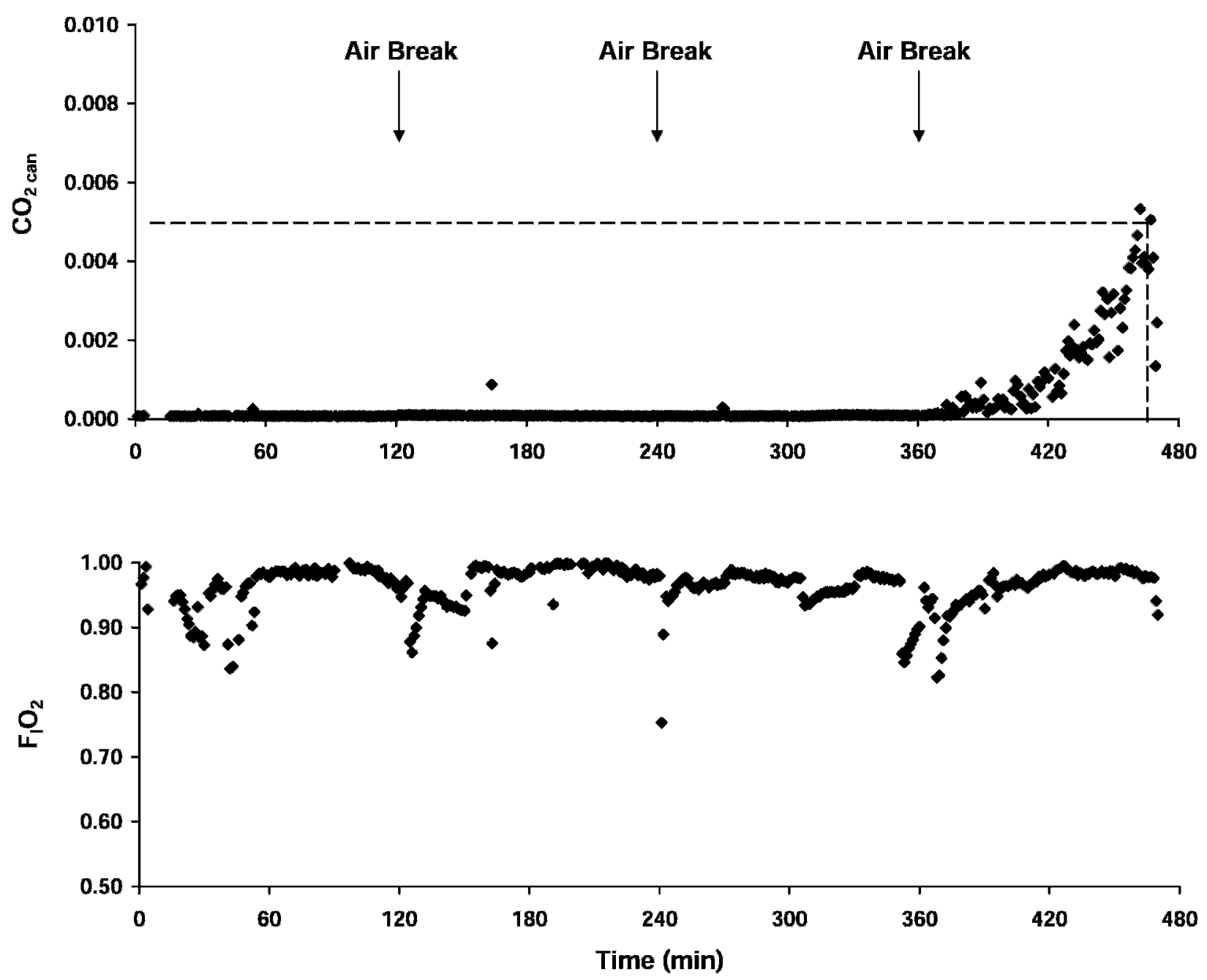

Figure 2. $\mathrm{CO}_{2 \text { can }}$ and $\mathrm{F}_{\mathrm{I}} \mathrm{O}_{2}$ profiles for subject 4. The dashed reference lines in the upper plot indicates the $3.8 \mathrm{~mm} \mathrm{Hg} \mathrm{CO}_{2}$ breakthrough threshold. Downward arrows indicate the timing of 10-minute air breaks.

through at the canister outlet in 8 hours, an initial rise in $\mathrm{CO}_{2}$ can was observed only for subject 1 (with a peak at $1.1 \mathrm{~mm} \mathrm{Hg}$ ).

Condensate forms as warm, humidified exhalation gas travels through the relatively cool circuit. Accumulation in the tubing can restrict gas flow and increase breathing resistance. Condensate was drained from the tubing during every air break. Condensate accumulation removed from the circuit over the course of the trial was $100 \pm$ $38 \mathrm{~mL}$.

A high $\mathrm{F}_{\mathrm{I}} \mathrm{O}_{2}$ was maintained in all trials. The mean $\mathrm{F}_{\mathrm{I}} \mathrm{O}_{2}$ was $0.95 \pm 0.04$ (Table 2; Figure 3). Perturbations in inspired concentration commonly indicate mask leakage. The lowest mean $\mathrm{F}_{\mathrm{I}} \mathrm{O}_{2}$ value $(0.93)$ was observed for subjects 2 and 6 . Subject 2 was a woman with a relatively small face. Subject 6 had a beard, a feature known to compromise mask seal. A water soluble gel
(K-Y Jelly; Johnson \& Johnson, New Brunswick, NJ) was applied to improve the seal for subject 6 only.

The mean measured oxygen flow was $1.06 \pm 1.36$ $\mathrm{L} \cdot \mathrm{min}^{-1}$ (Table 2; Figure 4). The high SD reflected the influence of the purge periods during individual trials. The trial averaged $\mathrm{O}_{2}$ flow was $1.00 \pm 0.17 \mathrm{~L} \cdot \mathrm{min}^{-1}$, reflecting low variability between trials.

Mean maximal $\mathrm{Pm}_{\text {in }}$ (Figure 5) was $-5.2 \pm 1.9 \mathrm{~cm}$ $\mathrm{H}_{2} \mathrm{O}$ (range, -1.3 to $-14.8 \mathrm{~cm} \mathrm{H}_{2} \mathrm{O}$ ). Mean maximal $\mathrm{Pm}_{\mathrm{ex}}$ was $6.5 \pm 1.9 \mathrm{~cm} \mathrm{H}_{2} \mathrm{O}$ (range, $1.8-16.6 \mathrm{~cm} \mathrm{H}_{2} \mathrm{O}$ ). The first 2 trials and the first 2 hours of the third trial were conducted without an expiratory valve at the distal end of the expiratory limb. The valve was added in an effort to eliminate high $\mathrm{F}_{\mathrm{I}} \mathrm{CO}_{2}$ values. The $\mathrm{F}_{\mathrm{I}} \mathrm{CO}_{2}$ dropped from 0.031 to 0.014 in the trials where an exhalation valve was in place. $\mathrm{F}_{\mathrm{I}} \mathrm{O}_{2}$ levels were unaffected. The additional valve increased maximal expiratory pres- 


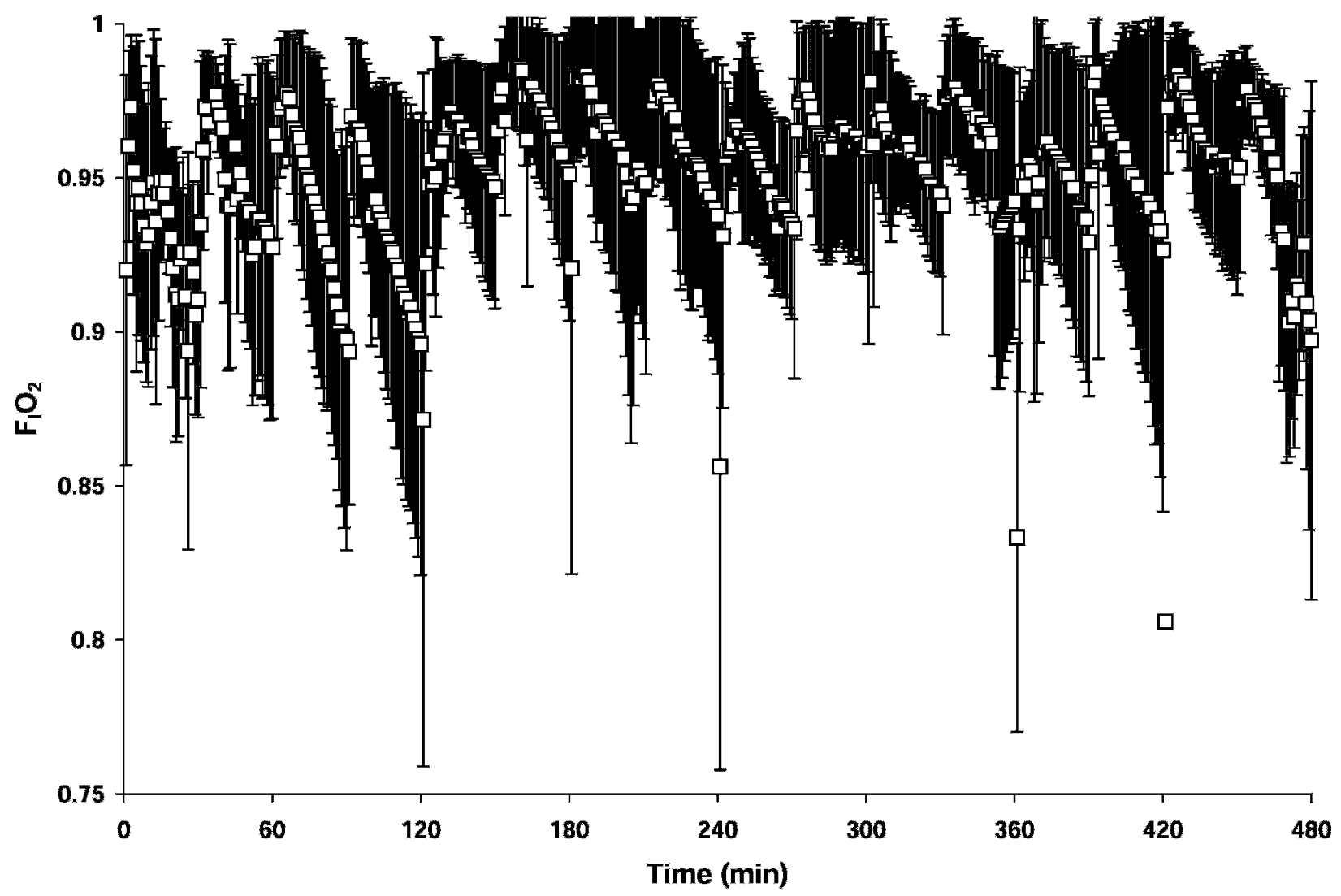

Figure 3. $\quad \mathrm{F}_{\mathrm{I}} \mathrm{O}_{2}$ (mean $\pm \mathrm{SD}$ ) for all trials. The extremely low values at 120,240 , and 360 minutes indicate where the mask seal was broken at the start of the air break.

sure by an average of 0.5 and $1.6 \mathrm{~cm} \mathrm{H}_{2} \mathrm{O}$, respectively, in the 2 cases where pressures were measured with and without the valve.

The temperature of gas in closed-circuit rebreathers tends to be high because of the exothermic nature of the reaction between $\mathrm{CO}_{2}$ and the scrubber material. Mean maximal $\mathrm{T}_{\mathrm{m}}$ was $32.9 \pm 0.9^{\circ} \mathrm{C}$ (range, $31.3-33.9^{\circ} \mathrm{C}$ ), and mean maximal $\mathrm{T}_{\text {can }}$ was $36.1 \pm 1.3^{\circ} \mathrm{C}$ (range, 33.6$\left.37.2^{\circ} \mathrm{C}\right) . \mathrm{T}_{\mathrm{m}}$ was inversely related to $\mathrm{O}_{2}$ flow and directly related to $\mathrm{T}_{\text {can }}$.

\section{Discussion}

Closed-circuit oxygen rebreathing systems can provide very high $\mathrm{F}_{\mathrm{I}} \mathrm{O}_{2}$ with extremely modest oxygen flow rates. The current trials evaluated the preproduction, second-generation $\mathrm{REMO}_{2}$ device under controlled conditions.

The device provided a high $\mathrm{F}_{\mathrm{I}} \mathrm{O}_{2}$ at a very low mean $\mathrm{O}_{2}$ flow rate; both values were comparable with unpublished test results with the first-generation unit. Maintenance of such a high $\mathrm{F}_{\mathrm{I}} \mathrm{O}_{2}$ requires constant vigilance. The greatest source of leakage is the mask, which will become uncomfortable with prolonged use. Care must be taken to minimize displacement of the mask, often a result of subject fidgeting. While aggressive management will minimize leaks, transient compromise should be expected. Inspired fractions can fall dramatically because of air entrainment when the mask seal is broken or if the mask fit is poor, possibly caused by size or shape of the face or the presence of a beard.

High flow purge periods have a high oxygen cost but are important to ensure that inert gas flushed from the body during oxygen breathing does not accumulate in the circuit. Inert gas will be flushed out of all persons breathing on the circuit, but more so for those with elevated inert gas loads after diving. We evaluated the purge procedure provided with the device. It was clearly adequate to preserve a high $\mathrm{F}_{\mathrm{I}} \mathrm{O}_{2}$ under the conditions tested. This is important because the oxygen content is not monitored during normal operation. The remarkably low total oxygen use of the system should reduce the need to sacrifice any safety margin in an attempt to optimize purge flow rates under less controlled conditions. Substantial leakage from the mask should be expected during periods with the highest purge flow rate. 


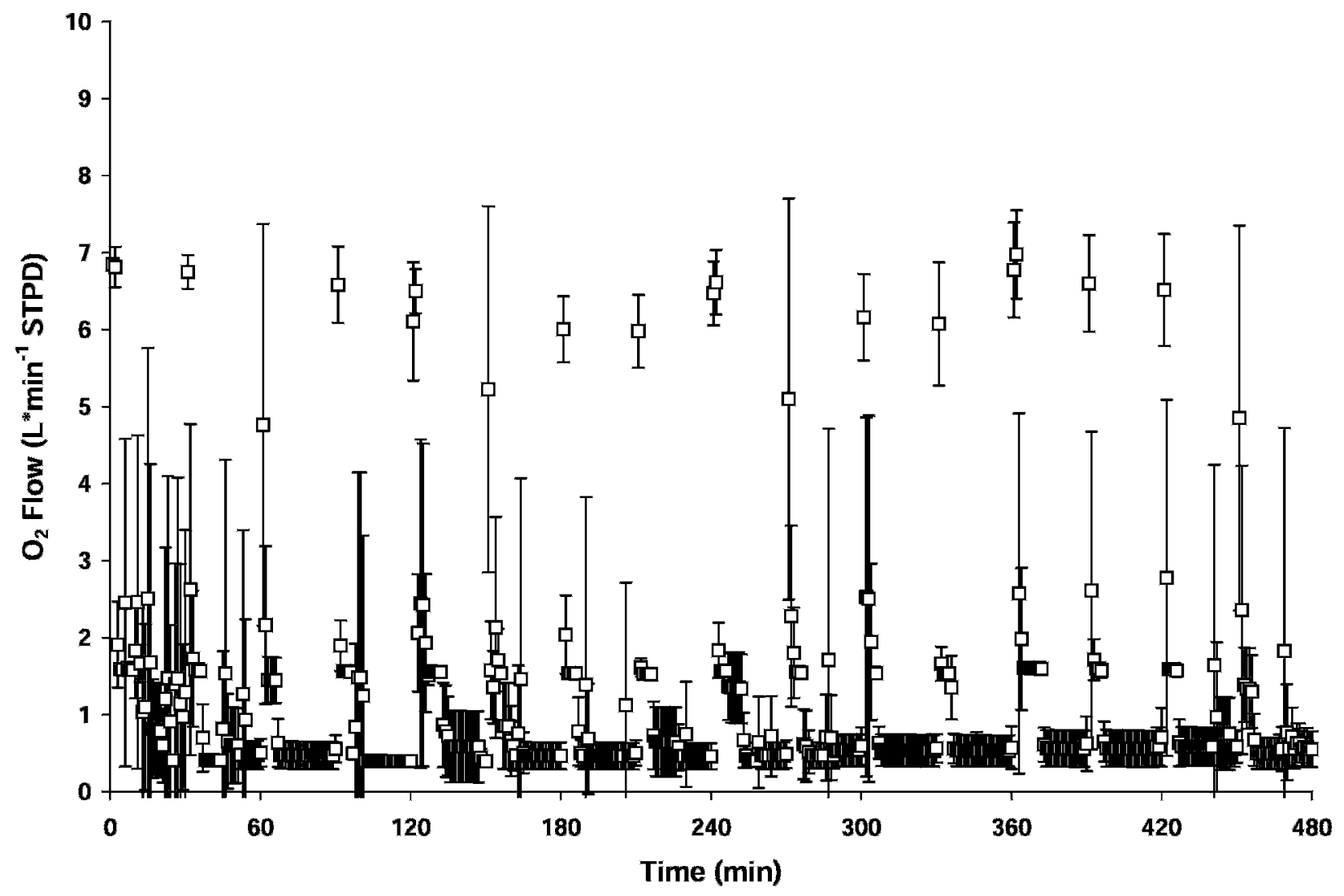

Figure 4. Measured $\mathrm{O}_{2}$ flow (mean $\pm \mathrm{SD}$ ) for all trials.

High breathing resistance is one of the common complaints lodged against closed-circuit rebreathing systems. ${ }^{6}$ Maximum circuit pressure in the portable systems is typically limited with PEEP valves ${ }^{1,2,7}$ to partially control breathing resistance. Measures of breathing resistance are not available for these systems. International Standards Organization (ISO) standards for emergency escape breathing devices for shipboard use call for machine tests of breathing resistance. ${ }^{8}$ Based on a simulated $\mathrm{V}_{\mathrm{E}}$ of $35 \mathrm{~L} \cdot \mathrm{min}^{-1}$, peak inspiratory pressures are not to exceed $-7.6 \mathrm{~cm} \mathrm{H}_{2} \mathrm{O}$, and peak expiratory pressures are not to exceed $+7.6 \mathrm{~cm} \mathrm{H}_{2} \mathrm{O}$. While not directly comparable with our manned tests with mean $\mathrm{V}_{\mathrm{E}}$ of approximately one third the ISO test rate (Table 1), the ISO standards do provide a foundation for reference. Mean peak pressures were within these limits for both inspiration and expiration, but maximal peak pressures exceeded the limits, particularly during purge periods when the circuit was under increased pressure. The addition of the second one-way valve early in the trials increased the overall resistance, but it was necessary to reduce rebreathing from the expiratory limb of the circuit. Although the breathing resistance was well tolerated, some respiratory fatigue can be expected, particularly during purge periods. Providing additional perspective, the second-generation $\mathrm{REMO}_{2}$ had substantially lower resistance than the first-generation device. Mean maximum $\mathrm{Pm}_{\text {in }}$ was $22 \%$ lower and $\mathrm{Pm}_{\mathrm{ex}}$ was $29 \%$ lower. Breathing resistance may be a much more important factor to a distressed patient.

One development goal for the $\mathrm{REMO}_{2}$ was to provide a $\mathrm{CO}_{2}$ absorbent duration of 6 hours. The first-generation device delivered this with smaller- to moderatesized subjects but fell short with larger subjects. The time to scrubber canister breakthrough was dramatically increased with the second-generation system. The mean scrubber mass was $8 \%$ higher, but the improvement was far greater. We could not quantify the magnitude of the improvement in our trials. The longest time to breakthrough observed in the first-generation evaluation was 8 hours and 4 minutes for a 59-kg subject. The shortest time was 3 hours and 49 minutes for a 123-kg subject. The shortest time to breakthrough in the second-generation trials was 7 hours and 50 minutes for a 104-kg subject. The a priori plan to limit the trial duration to 8 hours proved to be insufficient to evaluate the limits of the new scrubber.

A major limitation of this and many other rebreather 


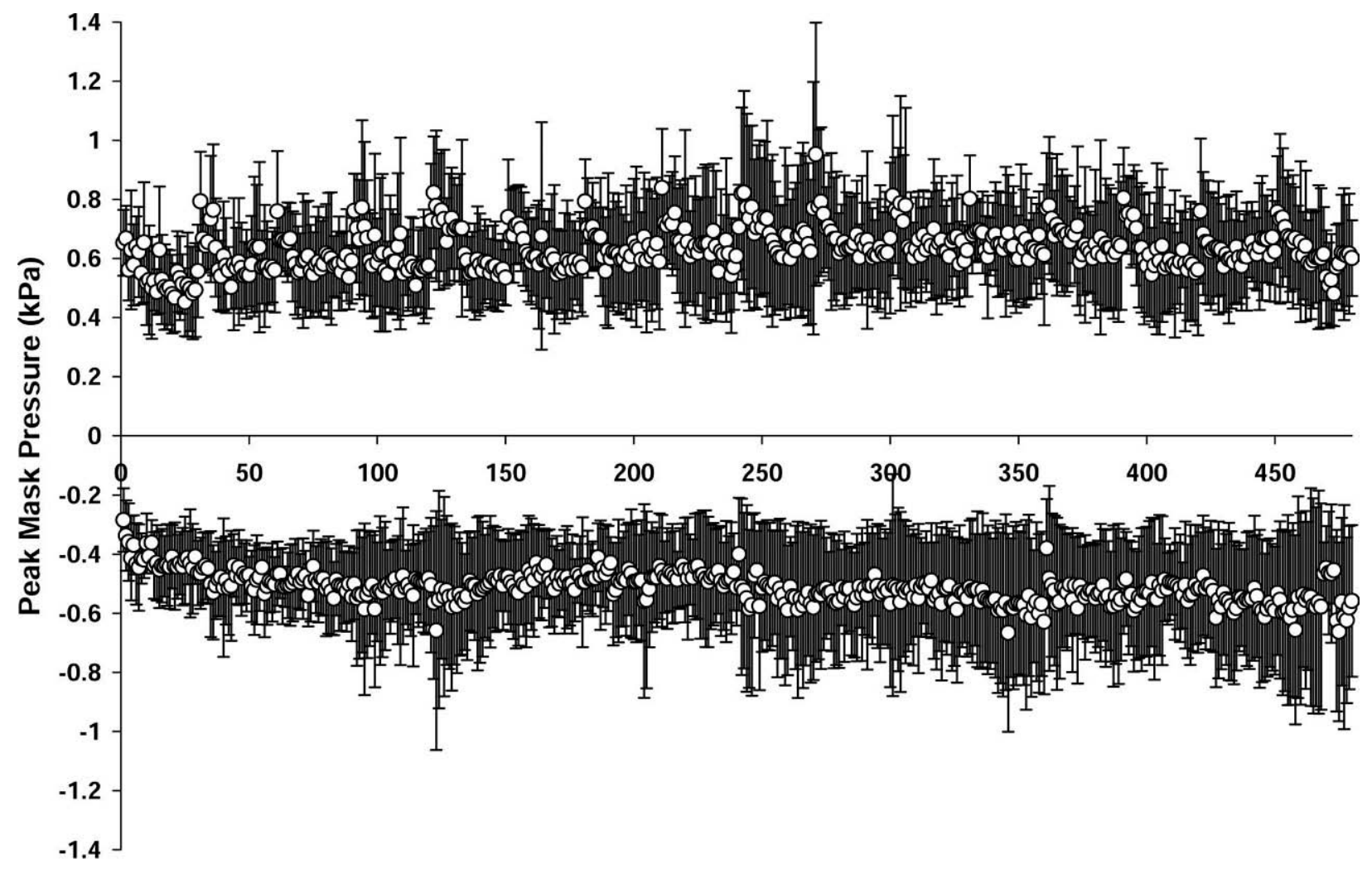

Time (min)

Figure 5. Mean $\pm \mathrm{SD}$ maximum $\mathrm{Pm}_{\mathrm{ex}}$ and $\mathrm{Pm}_{\mathrm{in}}$ for all trials.

devices is the inability to monitor scrubber canister status. Manufacturers can impregnate the scrubber insert with a dye that displays a color change when saturated to allow estimation of remaining time, but this feature was not incorporated into the current device. $\mathrm{CO}_{2}$ monitors could also be incorporated, but these are not commonly available. Direct monitoring and cautious use are needed to ensure that patients are not allowed to breathe on circuits with potentially exhausted scrubber material or oxygen supply. Persons with a high level of consciousness may remove the mask as hypercapnia or hypoxia develop, but persons with reduced levels of conscious are at significant risk. Incorporation of continuous gas fraction monitoring capability will be an important next step for rebreathing devices.

The draft standards from $\mathrm{ISO}^{8}$ set a $50^{\circ} \mathrm{C}$ limit on inhalation gas temperature. Inspired temperatures exceeding $40^{\circ} \mathrm{C}$ can be associated with subjective discomfort. The maximum temperature measured near the mouth in these trials remained well below the termination criterion of $40^{\circ} \mathrm{C}$. High inspired temperatures will not always be problematic. Warm, humidified inspired gas may provide a welcome augmentation of rewarming in some circumstances. Given a temperature gradient be- tween the circuit temperature and the environment, extension or collapse of the expandable circuit tubing could be used to partially regulate the inspired temperature. The effectiveness of this practice was not evaluated in our trials.

Our evaluation of the preproduction, second-generation $\mathrm{REMO}_{2}$ focused on performance characteristics during controlled use. We did not evaluate the device for component durability, materials safety, response to temperature cycling or vibration, absorbent material dusting, absorbent shelf life, or packaging considerations. Although we were unable to assess subjects stressed by disease or device performance under less controlled field conditions, we were able to show that the system was able to deliver a consistently high $\mathrm{FIO}_{2}$ with an extremely low oxygen flow rate. These results should encourage further field trials and materials tests to ensure a robust and effective device with life-saving potential.

\section{Conclusion}

The preproduction, second-generation $\mathrm{REMO}_{2}$ closedcircuit oxygen rebreathing system was well tolerated by healthy subjects during 8-hour laboratory evaluation tri- 
als. The device provided high mean inspired oxygen fractions at low mean oxygen flow rates, relatively modest mean maximal inspired and expired pressures, and excellent scrubber canister duration. Further evaluation under more extreme field conditions and with a patient population is warranted.

\section{Acknowledgments}

The authors thank Ken F. Haas, Gene W. Hobbs, Eric A. Schinazi, and Beth M. Terpolilli for technical support. This work was supported by Divers Alert Network.

\section{References}

1. Viegas OJ, Cummins DF, Shumacker CA. Portable ventilation system for transport of critically ill patients. Anesth Analg 1981;60:760-761.

2. Wendling J. Normobaric oxygenation in dive accidents: a challenge for the developers of oxygen delivery systems. SPUMS J 1997;27:101-104.

3. Mutzbauer TS, Neubauer B, Mueller PHJ, Tetzlaff K. Modification of the closed circuit underwater breathing apparatus LAR V makes it suitable for cardiopulmonary resuscitation (CPR). Resuscitation 1998;39:75-80.

4. Jackson AS, Pollock ML. Practical assessment of body composition. Phys Sports Med 1985;13:76-90.

5. Nuckols ML, Sarich AJ, Tucker WC. Life Support Systems Design: Diving and Hyperbaric Applications. Needham Heights, MA: Simon and Schuster; 1996.

6. Windsor JS, Rodway GW, Dick J. The use of closed-circuit oxygen in the Himalayas. High Alt Med Biol 2005;6: 263-269.

7. Lanier WL, Weeks DB. Portable semi-closed-circuit for prolonged oxygen administration in aircraft (letter). Anesthesiology 1985;63:116-118.

8. International Standards Organization. Ships and Marine Technology Breathing Apparatus for Ship-Part 1: Emergency Escape Breathing Devices (EEBD) for Shipboard Use. Geneva, Switzerland: ISO/CD 2326 9-1, 2002. 